\title{
SIMULATION OF QUEUE PATIENT SERVICE
}

\author{
Hendra Cipta \\ Department of Mathematics \\ UINSU Medan \\ hendracipta@uinsu.ac.id
}

\begin{abstract}
Queue is one of the phenomena that occur in everyday activities experienced by everyone. As a result of this queue many people turn to other places to avoid a queue and get more leverage. The purpose of this study is to study the performance of the queue system by modeling a single queue simulation. From the analysis of distribution test calculation will be obtained by queuing model. The measured system parameters are expected average speed velocity, average service speed expectation, chance of busy period, probability of all patient service in system, expectation of queue length, expectation of waiting time in system, and waiting expectation in queue.
\end{abstract}

Keywords: distribution test, queuing model, and system parameters

Abstrak. Antrian merupakan salah satu fenomena yang terjadi dalam aktifitas seharihari dialami oleh setiap orang. Akibat dari antrian ini banyak orang beralih ke tempat lain untuk menghindari suatu antrian dan mendapatkan pelayanan yang lebih maksimal. Tujuan penelitian ini adalah mempelajari kinerja sistem antrian dengan cara memodelkan simulasi antrian tunggal. Dari analisis perhitungan uji distribusi akan diperoleh model antriannya. Parameter sistem yang diukur adalah ekspektasi kecepatan pertibaan rata-rata, ekspektasi kecepatan pelayanan rata-rata, peluang masa sibuk, probabilitas semua pelayanan pasien dalam sistem, ekspektasi panjang antrian, ekspektasi waktu menunggu dalam sistem, dan ekspektasi menunggu dalam antrian.

Kata kunci: uji distribusi, model antrian, dan parameter sistem 


\section{PENDAHULUAN}

Dalam model-model antrian, kedatangan pelanggan dan waktu pelayanan dijelaskan dalam bentuk distribusi probabilitas yang umumnya disebut sebagai distribusi kedatangan (arrival distribution) dan distribusi waktu pelayanan (service time distribution). Selain kedua faktor tersebut ada faktor lain yang juga cukup penting dalam pengembangan model-model antrian diantaranya rancangan sarana pelayanan, peraturan pelayanan dan prioritas pelayanan, ukuran antrian, dan perilaku manusia menjadi hal yang tidak terlepas dari masalah antrian ini.

Faktor ketidakpastian (randomize) juga sangat berpengaruh dalam perilaku sistem pelayanan. Dimana dalam sistem pelayanan tersebut baik tingkat kedatangan pelanggan maupun tingkat pelayanan sama-sama mempunyai sifat tidak pasti (random). Salah satu cara yang biasa digunakan untuk mengamati perilaku sistem yang mengandung faktor ketidakpastian (randomize) yaitu menggunakan model simulasi. Sistem yang besar dan kompleks menyebabkan simulasi sebagai alat analisis untuk pengambilan keputusan menjadi semakin populer dan diperlukan (Pangestu: 1995).

Simulasi berusaha mempresentasikan sistem nyata yang ada dengan presisi yang lebih mudah untuk diamati dibandingkan jenis model lain. Dengan simulasi memungkinkan untuk dapat mengamati bagaimana sistem yang dipresentasikan dalam model ini berperilaku. Dengan kata lain model simulasi yang baik adalah model simulasi yang tidak hanya berorientasi pada output dari sebuah sistem, melainkan bagaimana model tersebut dapat menjelaskan karakteristik dan perubahan sistem dari waktu ke waktu. Semakin mampu model simulasi menirukan sistem nyatanya maka semakin baik model tersebut.

Suatu proses antrian (queueing process) adalah suatu proses yang berhubungan dengan kedatangan seorang pelanggan pada suatu fasilitas pelayanan, kemudian menunggu dalam suatu baris (antrian) jika semua pelayannya sibuk, dan akhirnya meninggalkan fasilitas tersebut (Siswanto. 2007)

Penelitian ini membahas masalah antrian pada klinik LIA. Setiap harinya pasien banyak datang ke tersebut untuk berobat sehingga dengan banyaknya pasien yang berdatangan tersebut maka terjadi kesibukan pelayanan. Karena adanya permasalahan antrian pada klinik LIA ini maka diadakan penelitian secara sistematis untuk menganalisis masalah antrian tersebut. Sehingga pada akhirnya masalah antrian tersebut dapat dikurangi atau bahkan dapat dicegah sehingga pasien puas terhadap pelayanan yang diberikan dan dari pihak klinik sendiri dapat memberikan pelayanan yang optimal. 


\section{TINJAUAN PUSTAKA}

\section{Sistem Antrian}

Sistem antrian dapat dijelaskan sebagai kedatangan pelanggan atau unit-unit yang membutuhkan pelayanan pada suatu fasilitas pelayanan. Pelanggan bergabung pada barisan penungguan (antrian) untuk dilayani. Setelah mendapat pelayanan, pelanggan dapat meninggalkan antrian tersebut. Dengan demikian dapat dibayangkan bila pelanggan membutuhkan waktu menunggu yang cukup lama maka akan diperoleh persentase waktu menganggur yang kecil, yang berarti sama sekali tidak ada waktu menganggur pada pelayanan tersebut (Thomas J. Kakiay: 2004).

\section{Model-model Antrian}

Sri Mulyono (2004:287) menerangkan bahwa proses antrian pada umumnya dikelompokkan kedalam empat model yakni:

Single Channel, Single Phase

Sistem antrian:

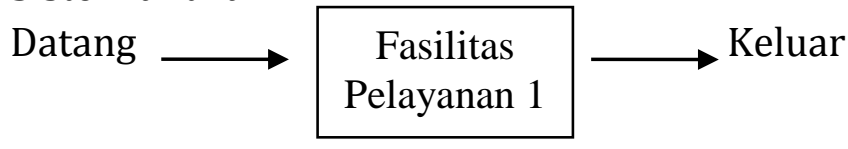

Single Channel, Multy Phase

Sistem antrian:

Datang

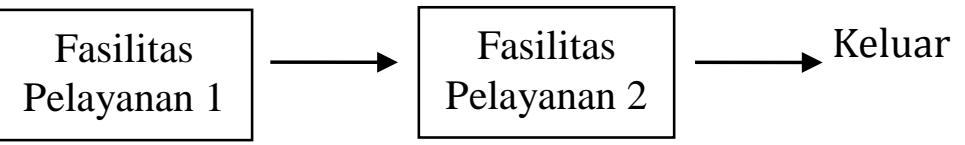

Multy Channel, Single Phase

Sistem antrian:

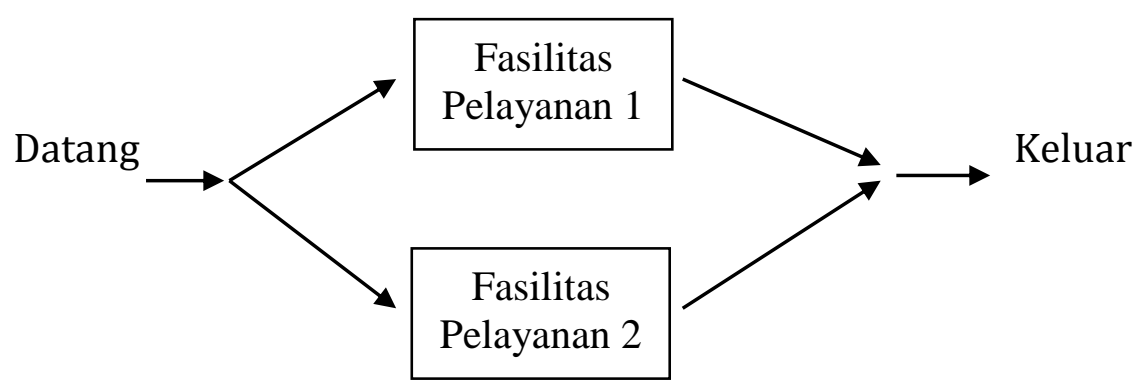




\section{Multy Channel, Multy Server}

Sistem antrian:

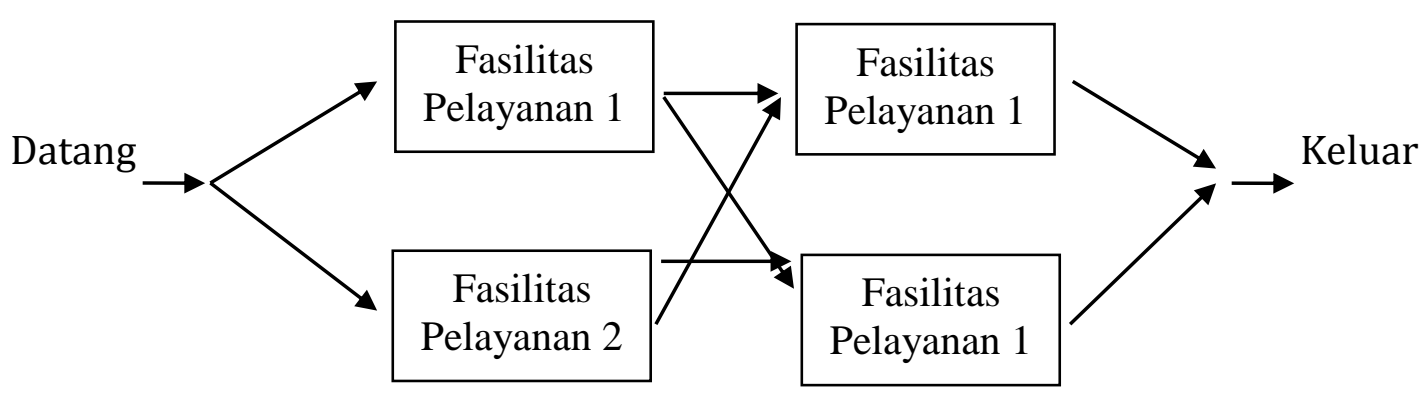

\section{Terminologi dan Notasi}

Terminologi:

1. Keadaan sistem merupakan banyaknya aktivitas pelayanan yang melayani satuan pelanggan dalam sistem.

2. Panjang antrian merupakan banyaknya satuan yang berada dalam sistem dikurangi dengan jumlah satuan yang sedang dijalani (Thomas J. Kakiay: 2004).

Notasi:

$n \quad=$ jumlah satuan pasien dalam sistem antrian pada waktu $t$

$c \quad=$ jumlah satuan pelayanan

$P_{n}(t)=$ peluang bahwa ada $n$ pasien yang masuk antrian dalam waktu $t$

$\lambda=$ tingkat kedatangan

$\frac{1}{\lambda} \quad=$ rata-rata kedatangan pelanggan

$\lambda \Delta t=$ peluang ada satu satuan pasien yang masuk dalam antrian selama waktu $t$

$\mu \quad=$ tingkat pelayanan

$\frac{1}{\mu} \quad=$ rata-rata waktu pelayanan

$\mu \Delta t \quad=$ peluang ada satu satuan pasien yang selesai dilayani selama waktu $t$

$\rho \quad=$ tingkat kesibukan sistem

$c \mu \quad=$ faktor untuk fasilitas pelayanan $c$

$L \quad=$ ekspektasi panjang garis

$L_{q} \quad=$ ekspektasi panjang antrian

$W \quad=$ ekspektasi waktu menunggu dalam sistem

$W_{q} \quad=$ ekspektasi menunggu dalam antrian 


\section{HASIL DAN PEMBAHASAN}

\section{Pengumpulan Data}

Data yang digunakan dalam penelitian ini adalah dari yang diperoleh dari pengamatan langsung pada klinik Bidan LIA yang dilakukan selama seminggu. Dari pengumpulan data dilapangan maka diperoleh jumlah kedatangan pasien sebagai berikut:

Tabel 1. Rangkuman Data Keadaan Klinik Dalam 1 Minggu (jam 15.00-17.00)

\begin{tabular}{|c|c|c|c|c|c|c|c|c|c|c|c|c|}
\hline Hari & \multicolumn{2}{|c|}{ Senin } & \multicolumn{2}{|c|}{ Selasa } & \multicolumn{2}{|c|}{ Rabu } & \multicolumn{2}{|c|}{ Kamis } & \multicolumn{2}{|c|}{ Jumat } & \multicolumn{2}{|c|}{ Sabtu } \\
\hline $\begin{array}{l}\text { Jumlah } \\
\text { pasien }\end{array}$ & $\begin{array}{c}\mathrm{P} \\
\text { lam } \\
\mathrm{a}\end{array}$ & $\begin{array}{c}\mathrm{P} \\
\text { bar } \\
\mathrm{u}\end{array}$ & $\begin{array}{c}\mathrm{P} \\
\text { lam } \\
\mathrm{a}\end{array}$ & $\begin{array}{c}\mathrm{P} \\
\text { bar } \\
\mathrm{u}\end{array}$ & $\begin{array}{c}\mathrm{P} \\
\text { lam } \\
\mathrm{a}\end{array}$ & $\begin{array}{c}\mathrm{P} \\
\text { bar } \\
\mathrm{u}\end{array}$ & $\begin{array}{c}\mathrm{P} \\
\mathrm{lam} \\
\mathrm{a}\end{array}$ & $\begin{array}{c}\mathrm{P} \\
\text { bar } \\
\mathrm{u}\end{array}$ & $\begin{array}{c}\mathrm{P} \\
\operatorname{lam} \\
\mathrm{a}\end{array}$ & $\begin{array}{c}\mathrm{P} \\
\text { bar } \\
\mathrm{u}\end{array}$ & $\begin{array}{c}\mathrm{P} \\
\text { lam } \\
\mathrm{a}\end{array}$ & $\begin{array}{c}\mathrm{P} \\
\text { bar } \\
\mathrm{u}\end{array}$ \\
\hline & 25 & 10 & 20 & 12 & 21 & 11 & 20 & 13 & 18 & 14 & 20 & 18 \\
\hline $\begin{array}{c}\text { Lama } \\
\text { pengamata } \\
\text { n (jam) }\end{array}$ & 2 & 2 & 2 & 2 & 2 & 2 & 2 & 2 & 2 & 2 & 2 & 2 \\
\hline
\end{tabular}

Tabel 2. Data Tingkat Kedatangan Pasien Setiap Jam Dalam 1 Minggu

\begin{tabular}{|c|c|c|c|c|c|c|c|c|c|c|c|c|}
\hline Hari & \multirow{2}{*}{\multicolumn{2}{|c|}{ Senin }} & \multirow{2}{*}{\multicolumn{2}{|c|}{ Selasa }} & \multirow{2}{*}{\multicolumn{2}{|c|}{ Rabu }} & \multirow{2}{*}{\multicolumn{2}{|c|}{ Kamis }} & \multirow{2}{*}{\multicolumn{2}{|c|}{ Jumat }} & \multirow{2}{*}{\multicolumn{2}{|c|}{ Sabtu }} \\
\hline Wakt & & & & & & & & & & & & \\
\hline & $\begin{array}{c}\mathrm{P} \\
\text { lam } \\
\mathrm{a}\end{array}$ & $\begin{array}{c}\mathrm{P} \\
\text { bar } \\
\mathrm{u}\end{array}$ & $\begin{array}{c}\mathrm{P} \\
\text { lam } \\
\mathrm{a}\end{array}$ & $\begin{array}{c}\mathrm{P} \\
\text { bar } \\
\mathrm{u}\end{array}$ & $\begin{array}{c}\mathrm{P} \\
\text { lam } \\
\mathrm{a}\end{array}$ & $\begin{array}{c}\mathrm{P} \\
\text { bar } \\
\mathrm{u}\end{array}$ & $\begin{array}{c}\mathrm{P} \\
\text { lam } \\
\mathrm{a}\end{array}$ & $\begin{array}{c}\mathrm{P} \\
\text { bar } \\
\mathrm{u}\end{array}$ & $\begin{array}{c}\mathrm{P} \\
\text { lam } \\
\mathrm{a}\end{array}$ & $\begin{array}{c}\mathrm{P} \\
\text { bar } \\
\mathrm{u}\end{array}$ & $\begin{array}{c}\mathrm{P} \\
\text { lam } \\
\mathrm{a}\end{array}$ & $\begin{array}{c}\mathrm{P} \\
\text { bar } \\
\mathrm{u}\end{array}$ \\
\hline $\begin{array}{l}15.00- \\
16.00\end{array}$ & 21 & 7 & 15 & 5 & 13 & 6 & 13 & 9 & 13 & 8 & 8 & 8 \\
\hline $\begin{array}{l}16.00- \\
17.00\end{array}$ & 8 & 5 & 8 & 6 & 11 & 6 & 10 & 3 & 4 & 5 & 7 & 11 \\
\hline
\end{tabular}

Tabel 3. Data Rata-rata Waktu Pelayanan (dalam menit) Dalam 1 Minggu

\begin{tabular}{|c|c|c|c|c|c|c|c|c|c|c|c|c|}
\hline \multirow{3}{*}{$\begin{array}{c}\text { Hari } \\
\text { Wakt } \\
\mathrm{u}\end{array}$} & \multirow{3}{*}{\multicolumn{2}{|c|}{ Senin }} & \multirow{3}{*}{\multicolumn{2}{|c|}{ Selasa }} & \multirow{3}{*}{\multicolumn{2}{|c|}{ Rabu }} & \multirow{3}{*}{\multicolumn{2}{|c|}{ Kamis }} & \multirow{3}{*}{\multicolumn{2}{|c|}{ Jumat }} & \multirow{3}{*}{\multicolumn{2}{|c|}{ Sabtu }} \\
\hline & & & & & & & & & & & & \\
\hline & & & & & & & & & & & & \\
\hline & $\begin{array}{c}\mathrm{P} \\
\text { lam } \\
\mathrm{a}\end{array}$ & $\begin{array}{c}\mathrm{P} \\
\text { baru }\end{array}$ & $\begin{array}{c}\mathrm{P} \\
\operatorname{lam} \\
\mathrm{a}\end{array}$ & $\begin{array}{c}\mathrm{P} \\
\text { baru }\end{array}$ & $\begin{array}{c}\mathrm{P} \\
\text { lam } \\
\mathrm{a}\end{array}$ & $\begin{array}{c}\mathrm{P} \\
\text { baru }\end{array}$ & $\begin{array}{c}\mathrm{P} \\
\text { lam } \\
\mathrm{a}\end{array}$ & $\begin{array}{c}\mathrm{P} \\
\text { baru }\end{array}$ & $\begin{array}{c}\mathrm{P} \\
\text { lam } \\
\mathrm{a}\end{array}$ & $\begin{array}{c}\mathrm{P} \\
\text { baru }\end{array}$ & $\begin{array}{c}\mathrm{P} \\
\text { lam } \\
\mathrm{a}\end{array}$ & $\begin{array}{c}\mathrm{P} \\
\text { baru }\end{array}$ \\
\hline
\end{tabular}




\begin{tabular}{|c|c|c|c|c|c|c|c|c|c|c|c|c|}
\hline 15.0 & & & & & & & & & & & & \\
$0-$ & 5,75 & 5,00 & 5,00 & 5,62 & 5,76 & 4,83 & 4,51 & 5,16 & 6,00 & 5,20 & 5,76 & 5,00 \\
16.0 & 0 & 0 & 0 & 5 & 9 & 3 & 5 & 7 & 0 & 0 & 7 & 0 \\
0 & & & & & & & & & & & & \\
\hline $\begin{array}{c}16.0 \\
0-\end{array}$ & 5,00 & 6,27 & 4,50 & 5,80 & 6,00 & 5,66 & 6,18 & 5,66 & 5,50 & 5,66 & 6,62 & 5,00 \\
17.0 & 0 & 3 & 0 & 0 & 0 & 7 & 2 & 7 & 0 & 7 & 5 & 0 \\
0 & & & & & & & & & & & & \\
\hline
\end{tabular}

\section{Pengolahan Data}

Untuk menghitung nilai dari $\lambda$ data pengamatan pada $h_{1}, h_{2}, h_{3}, \ldots, h_{6}$ terlebih dahulu ditentukan nilai kemungkinan waktu pelayanan yang diharapkan dengan distribusi eksponensial $x^{2}=\sum \frac{\left(x_{i}-\bar{x}\right)^{2}}{\bar{x}}$.

Tabel 4. Rata-rata Kecepatan Kedatangan Pasien Lama

\begin{tabular}{|c|c|c|c|c|c|c|}
\hline Hari & $\mathrm{h}_{1}$ & $\mathrm{~h}_{2}$ & $\mathrm{~h}_{3}$ & $\mathrm{~h}_{4}$ & $\mathrm{~h}_{5}$ & $\mathrm{~h}_{6}$ \\
\hline$\lambda$ & 14,5 & 11,5 & 11,5 & 11,5 & 8,5 & 12,5 \\
\hline
\end{tabular}

Tabel 5. Rata-rata Kecepatan Kedatangan Pasien Baru

\begin{tabular}{|c|c|c|c|c|c|c|}
\hline Hari & $\mathrm{h}_{1}$ & $\mathrm{~h}_{2}$ & $\mathrm{~h}_{3}$ & $\mathrm{~h}_{4}$ & $\mathrm{~h}_{5}$ & $\mathrm{~h}_{6}$ \\
\hline$\lambda$ & 6 & 5,5 & 6 & 6 & 6,5 & 9,5 \\
\hline
\end{tabular}

Tabel 6. Rata-rata Kecepatan Pelayanan Pasien Lama

\begin{tabular}{|c|c|c|c|c|c|c|}
\hline Hari & $\mathrm{h}_{1}$ & $\mathrm{~h}_{2}$ & $\mathrm{~h}_{3}$ & $\mathrm{~h}_{4}$ & $\mathrm{~h}_{5}$ & $\mathrm{~h}_{6}$ \\
\hline$\lambda$ & 0,121 & 0,210 & 0,114 & 0,141 & 0,114 & 0,110 \\
\hline$\lambda_{\text {harapan }}$ & 0,107 & 0,170 & 0,101 & 0,122 & 0,101 & 0,098 \\
\hline
\end{tabular}

Tabel 7. Rata-rata Kecepatan Pelayanan Pasien Baru

\begin{tabular}{|c|c|c|c|c|c|c|}
\hline Hari & $\mathrm{h}_{1}$ & $\mathrm{~h}_{2}$ & $\mathrm{~h}_{3}$ & $\mathrm{~h}_{4}$ & $\mathrm{~h}_{5}$ & $\mathrm{~h}_{6}$ \\
\hline$\lambda$ & 0,089 & 0,087 & 0,095 & 0,092 & 0,092 & 0,100 \\
\hline$\lambda_{\text {harapan }}$ & 0,081 & 0,079 & 0,086 & 0,083 & 0,083 & 0,090 \\
\hline
\end{tabular}

\section{Simulasi Model}

Metode simulasi merupakan salah satu metode yang lebih efektif untuk memecahkan masalah antrian. Untuk simulasi waktu kedatangan, waktu pelayanan yang bersifat random. Bilangan random digunakan untuk menentukan berapa lama waktu yang digunakan sesuai dengan jenis distribusinya. Untuk membangkitkan 
bilangan random ini digunakan alat bantu Microsoft Excel untuk membangkitkan bilangan random antara $0-1$.

\section{Waktu Pemeriksaan Pasien Lama}

Dari uji distribusi diketahui waktu pemeriksaan berdistribusi eksponensial. Diketahui waktu rata-rata pemeriksaan 0,696 menit.

Jadi fungsi distribusi yaitu: $t=-\mu \ln (u)$

Algoritma untuk menentukan $x$

1. Bangkitkan bilangan random $u(0,1)$

2. $x=-0,696 \ln (u)$

3. Diperoleh $x$

Tabel 8. Simulasi Waktu Pemeriksaan Pasien Lama

\begin{tabular}{|c|c|c|}
\hline \multirow{2}{*}{$\begin{array}{c}\text { Kedatangan } \\
\text { pasien lama }\end{array}$} & Bilangan Random $(u)$ & $\begin{array}{c}\text { Rata-rata waktu } \\
\text { pemeriksaan }\end{array}$ \\
\cline { 2 - 3 } & & $x=-0,696 \ln (u)$ \\
\hline 1 & 0.72674428 & 0.222149705 \\
\hline 2 & 0.063156439 & 1.922449765 \\
\hline 3 & 0.407359543 & 0.625049124 \\
\hline 4 & 0.776377311 & 0.17616919 \\
\hline 5 & 0.216920325 & 1.063644711 \\
\hline 6 & 0.539525081 & 0.42947794 \\
\hline 7 & 0.47196482 & 0.522592169 \\
\hline 8 & 0.153092528 & 1.306192097 \\
\hline 9 & 0.145784948 & 1.340233401 \\
\hline 10 & 0.29538802 & 0.848747963 \\
\hline \multicolumn{2}{|c|}{ Jumlah } & 8.456706065 \\
\hline \multicolumn{2}{|c|}{ Rata-rata } & 1.537582921 \\
\hline
\end{tabular}

\section{Waktu Pemeriksaan Pasien Baru}

Dari uji distribusi diketahui waktu pemeriksaan berdistribusi eksponensial. Diketahui waktu rata-rata pemeriksaan 0,555 menit.

Jadi fungsi distribusi yaitu:

$$
t=-\mu \ln (u)
$$

\section{Algoritma untuk menentukan $x$}

1. Bangkitkan bilangan random $u(0,1)$

2. $x=-0,555 \ln (u)$

3. Diperoleh $x$ 
Tabel 9. Simulasi Waktu Pemeriksaan Pasien Baru

\begin{tabular}{|c|c|c|}
\hline \multirow{2}{*}{$\begin{array}{c}\text { Kedatangan } \\
\text { pasien baru }\end{array}$} & Bilangan Random $(u)$ & $\begin{array}{c}\text { Rata-rata waktu } \\
\text { pemeriksaan }\end{array}$ \\
\cline { 2 - 3 } & & $x=-0,555 \ln (u)$ \\
\hline 1 & 0.309179782 & 0.651476956 \\
\hline 2 & 0.785280309 & 0.168233322 \\
\hline 3 & 0.658573667 & 0.29070451 \\
\hline 4 & 0.29706457 & 0.844808807 \\
\hline 5 & 0.017453664 & 2.817551159 \\
\hline 6 & 0.045472096 & 2.15109686 \\
\hline 7 & 0.101015861 & 1.595564506 \\
\hline 8 & 0.953348783 & 0.033251023 \\
\hline 9 & 0.953942902 & 0.032817417 \\
\hline 10 & 0.684895168 & 0.263428686 \\
\hline \multicolumn{2}{|c|}{ Rata-rata } & 8.848933247 \\
\hline
\end{tabular}

\section{Waktu Pembuatan Kartu Riwayat Kesehatan}

Dari uji distribusi diketahui pemeriksaan oleh bidan berdistribusi eksponensial. Diketahui waktu rata-rata pemeriksaan 0,5840 menit. Jadi fungsi distribusinya yakni:

Tabel 10. Simulasi Pembuatan Kartu Riwayat Kesehatan Pasien Baru

\begin{tabular}{|c|c|c|}
\hline \multirow{2}{*}{$\begin{array}{c}\text { Kedatangan } \\
\text { pasien baru }\end{array}$} & Bilangan Random $(u)$ & $\begin{array}{c}\text { Rata-rata waktu } \\
\text { pemeriksaan }\end{array}$ \\
\cline { 3 - 3 } & & $x=-0,5840 \ln (u)$ \\
\hline 1 & 0.007634301 & 2.847060677 \\
\hline 2 & 0.763347786 & 0.18794891 \\
\hline 3 & 0.875190314 & 0.092786485 \\
\hline 4 & 0.877939665 & 0.090603475 \\
\hline 5 & 0.594386842 & 0.362076546 \\
\hline 6 & 0.030954689 & 2.418760619 \\
\hline 7 & 0.072917083 & 1.822428907 \\
\hline 8 & 0.831103343 & 0.128760788 \\
\hline
\end{tabular}




\begin{tabular}{|c|c|c|}
\hline 9 & 0.785903968 & 0.167680788 \\
\hline 10 & 0.412736628 & 0.615922133 \\
\hline \multicolumn{2}{|c|}{ Jumlah } & 8.848933247 \\
\hline \multicolumn{2}{|c|}{ Rata-rata } & 1.608896954 \\
\hline
\end{tabular}

\section{Hasil Simulasi Dengan Teori Antrian}

Ekspektasi Kecepatan Pertibaan Rata-rata

Dari data diketahui:

$\lambda_{\text {lama }}=\frac{\text { jumlah pasien lama selama pengamatan }}{\text { waktu pengamatan }}$

$\lambda_{\text {lama }}=\frac{124}{12}=0,172$ per menit

$\lambda_{\text {baru }}=\frac{\text { jumlah pasien baru selama pengamatan }}{\text { waktu pengamatan }}$

$\lambda_{\text {baru }}=\frac{78}{12}=0,108$ per menit

$\lambda_{\text {gabungan }}=0,172+0,108=0,280$ pasien per menit

\subsubsection{Ekspektasi Kecepatan Pelayanan Rata-rata}

Lama pelayanan pasien baru = lama pemeriksaan dokter + lama pelayanan pembuatan kartu riwayat kesehatan. Lama pelayanan pasien baru $=1,60889+1,588=3,197$ menit.

$$
\begin{aligned}
& \mu_{\text {pasien lama }}=\frac{1}{\text { rata-rata waktu pelayanan pasien lama }} \\
& \mu_{\text {pasien lama }}=\frac{1}{1,5376}=0,650 \text { pasien per menit } \\
& \mu_{\text {pasien baru }}=\frac{1}{\text { rata-rata waktu pelayanan pasien baru }} \\
& \mu_{\text {pasien baru }}=\frac{1}{3,197}=0,313 \text { pasien per menit } \\
& \mu_{\text {gabungan }}=0,650+0,313=0,963
\end{aligned}
$$

3.4.2. Peluang Masa Sibuk

$$
\rho=\frac{\lambda}{\mu}=\frac{0,280}{0,963}=0,291
$$

3.4.3. Peluang Semua Pelayan Menganggur 


$$
P_{0}=\frac{\lambda}{\rho}=\frac{0,280}{0,291}=0,962
$$

3.4.4. Ekspektasi Panjang Antrian

$$
\begin{aligned}
& L_{q}=\frac{\lambda^{2}}{\mu(\mu-\lambda)} \\
& L_{q}=\frac{(0,280)^{2}}{0,962(0,962-0,280)}=0,143 \text { pasien per menit }
\end{aligned}
$$

3.4.5. Ekspektasi Panjang Garis

$L=L_{q}+\rho$

$L=0,143+0,290=0,433$ pasien per menit

3.4.6. Ekspektasi Waktu Menunggu Dalam Sistem

$W=\frac{L}{\lambda}=\frac{0,433}{0,280}=1,2$ menit

3.4.7. Ekspektasi Waktu Menunggu Dalam Antrian

$$
\begin{aligned}
& W_{q}=W-\mu \\
& W_{q}=1,2-0,963=0,237 \text { menit }
\end{aligned}
$$

\section{KESIMPULAN}

Dari simulasi yang dilakukan pada waktu kedatangan pasien, waktu pelayanan pasien, dan waktu pembuatan kartu riwayat kesehatan diperoleh data: ekspektasi kecepatan pertibaan rata-rata $\lambda=0,280$ pasien per menit, ekspektasi kecepatan pelayanan rata-rata $\mu=0,963$ pasien per menit, peluang masa sibuk $\rho=0,291$, probabilitas semua pelayanan menganggur atau tidak ada pasien dalam sistem $P_{0}=0,962$, ekspektasi panjang antrian $L_{q}=0,143$ pasien per menit, ekspektasi panjang garis $L=0,433$ pasien per menit, ekspektasi waktu menunggu dalam sistem $W=1,2$ menit, dan ekspektasi waktu menunggu dalam antrian $W_{q}=0,237$ menit. 


\section{DAFTAR PUSTAKA}

[1] Bain, L \& Engelhardt. (1992). Introduction to Probability and Mathematical Statistics: Second Edition. California: Duxbury Press.

[2] Bronson, Richard, 1983. Theory and Problems of Operations Reseach. Singapore: Mc. Graw Hill.

[3] Ecker, J., and Kupferschimd, M. 1988. Introduction to Operation Research. New York: John Wiley \& Sons.

[4] Gross, D \& Haris, C. M. 2008.Fundamental of Queueing Theory: Fourth edition. New Jersey: John Willey \& Sons, Inc.

[5] J. Kakiay, Thomas, 2004. Dasar Teori Antrian Untuk Kehidupan Nyata. Yogyakarta: ANDI.

[6] Mulyono, Sri. 2004. Riset Operasi. Jakarta: FE-UI.

[7] Narayan Bhat, U. 2008. Queueing Theory Modeling And Analysis In Applications, Boston: Birkhauser.

[8] Subagyo, Pangestu. 1995. Dasar-dasar Operasi Riset. Yogyakarta: BPPT.

[9] Siswanto. 2007. “Operation Research". Jilid II. Jakarta: Erlangga.

[10] Taha, H. 2007. Operations Research and Introduction. New Jersey: Pearson Education, Inc. 